\title{
Effects of microclimate and human parameters on outdoor thermal sensation in the high-density tropical context of Dhaka
}

\author{
$\operatorname{Tania~Sharmin~}^{1}$ (1) $\cdot$ Koen Steemers ${ }^{1}$ \\ Received: 6 December 2017 / Revised: 13 July 2018 / Accepted: 25 August 2018 / Published online: 12 September 2018 \\ (C) The Author(s) 2018
}

\begin{abstract}
A thermal comfort questionnaire survey was carried out in the high-density, tropical city Dhaka. Comfort responses from over 1300 subjects were collected at six different sites, alongside meteorological parameters. The effect of personal and psychological parameters was examined in order to develop predictive models. Personal parameters included gender, age, activity, professiontype (indoor or outdoor-based), exposure to air-conditioned space and sweat-levels. Psychological parameters, such as 'the reason for visiting the place' and 'next destination is air-conditioned', had statistically significant effects on thermal sensation. Other parameters, such as 'body type', 'body exposure to sun', 'time living in Dhaka', 'travelling in last_30 min', and 'hot food' did not have any significant impact. Respondents' humidity, wind speed and solar radiation sensation had profound impacts and people were found willing to adjust to the thermal situations with adaptive behaviour. Based on actual sensation votes from the survey, empirical models are developed to predict outdoor thermal sensation in the case study areas. Ordinal linear regression techniques are applied for predicting thermal sensation by considering meteorological and personal conditions of the field survey. The inclusion of personal and weather opinion factors produced an improvement in models based on meteorological factors. The models were compared with the actual thermal sensation using the cross-tabulation technique. The predictivity of the three models (meteorological, thermos-physiological and combined parameter) as expressed by the gamma coefficient were 0.575 , 0.636 and 0.727 , respectively. In all three models, better predictability was observed in the 'Slightly Warm' (71\% in meteorological model) and 'Hot' (64.9\% in combined parameter model) categories - the most important ones in a hot-humid climate.
\end{abstract}

Keywords Outdoor thermal comfort · Questionnaire survey · Thermal sensation vote (TSV) · Predictive model · Tropical climate

\section{Introduction}

Evidence suggests that urbanisation encourages economic growth (Turok \& McGranahan 2013); however, without proper planning, urbanisation can adversely affect the natural environment and public health conditions. The trend is more severe in rapidly urbanising developing nations in the tropics where

Part of a Special Issue on Subjective approaches to thermal perception

Electronic supplementary material The online version of this article (https://doi.org/10.1007/s00484-018-1607-2) contains supplementary material, which is available to authorized users.

Tania Sharmin ts531@cam.ac.uk

1 The Martin Centre for Architectural and Urban Studies, Department of Architecture, University of Cambridge, 1-5 Scroope Terrace, Cambridge CB2 1PX, UK limited resources for managing planning and investment are unable to lead to a sustainable urban growth. The unbridled urbanisation in many tropical cities has eradicated green-cover and intensified the vulnerability to climate change. Furthermore, declining air quality caused by the exhausts from traffic and industry, and the generation of urban heat islands (UHIs), caused by the unplanned growth of the built environment, have worsened the microclimatic conditions in tropical cities.

Adverse microclimatic conditions greatly affect the thermal comfort, health and wellbeing of people in urban outdoor spaces. For tropical countries in particular, the implications of thermal stress on health and productivity needs to be tackled largely by proper urban and building design details that are affordable. To address this need, recent studies have examined the relationship among microclimate, thermal comfort and human behaviour with the aim to provide guidelines and implications for outdoor space design and planning practice. Important studies in a tropical climate include da Silveira Hirashima et al. (2016); Ignatius et al. (2015); Villadiego \& Velay-Dabat (2014); Yang et al. 
(2013); Johansson et al. (2018), etc. which provide an extensive knowledge of the effects of outdoor climatic conditions on people's thermal sensation. However, there has been a limited amount of research in these areas focussing on the tropical megacity of Dhaka. As one of the worst victims of climate change, Dhaka is particularly vulnerable with poor outdoor microclimatic conditions exacerbated by the urban heat island (UHI) effect (Kotharkar et al. 2018; Santamouris \& Asimakopoulos 2001) and an elevated level of air pollution (Carlsen et al. 2018; Begum et al. 2011; Azad \& Kitada 1998). This makes outdoor comfort research particularly important for Dhaka, since outdoor spaces-users are exposed to severe heat stress during the most part of the year. The only scholarly work concerning outdoor thermal comfort and urban microclimate was carried out by (Ahmed 2003). The study, however, did not identify the impact of various parameters on outdoor thermal comfort other than the environmental ones. It mainly emphasised specific microclimatic features, such as the presence or absence of greenery, proximity to a river, etc. No prediction tool was proposed. This study, therefore, intends to contribute in understanding the impact of various personal and psychological parameters alongside meteorological parameters on thermal perception in order to be able to identify priorities in climate-responsive urban design.

Outdoor thermal comfort can be affected by a wide range of parameters. Environmental factors play the most important role in thermal sensation. However, people's ability to thermal adaptation through personal and cultural behavioural adjustments is significant. Similarly, thermal comfort research remains incomplete without consideration of physiological (genetic adaptation or acclimatisation) and psychological (habituation or expectation) factors (Brager and De Dear 1998; Knez et al. 2009; Lin 2009; Nikolopoulou and Steemers 2003; Nikolopoulou et al. 2001; Thorsson et al. 2004). These parameters indicate that people's thermal comfort sensation depend on climate, culture, personal and psychological backgrounds. It is, therefore, important to conduct field studies to examine outdoor thermal conditions and human thermal comfort perceptions in various places to complement existing knowledge on thermal comfort conditions in outdoor urban spaces.

Several studies have investigated the relation between meteorological variables and thermal sensation. For example, Nikolopoulou and Lykoudis (2006) have reported correlations between thermal sensation vote (TSV) and air temperature $(r=0.43)$ or globe temperature $(r=0.53)$. Their study advised that independent microclimatic parameters are unable to explain all variations in outdoor comfort conditions. Other studies, such as Villadiego and Velay-Dabat (2014), have reported correlations between TSV and air temperature $(r=0.305)$, relative humidity $(r=-0.117)$ and wind speed $(r=$ null).

In terms of personal parameters, studies have found that women are more sensitive to thermal conditions than men (Krüger \& Rossi 2011; Karjalainen 2007). In a more recent study, Kruger and Drach (2017) have identified gender effects to be insignificant whereas age was an important variable for open space users in Rio de Janeiro, Brazil. People aged over 55 were found to be vulnerable to heat increase (Pantavou et al. 2013). Responses from people with chronic asthma and various allergies were also examined in the same study along with people's psychological states. Those who were alone in the interview site were found to be more likely to express their thermal sensations in the extreme categories than those who had company.

Yang et al. (2013) have tested the impact of visiting purpose and frequency, exposure time and exposure to air-conditioned space prior to the interview. Only exposure to air-conditioned space was found to have a significant impact on thermal sensation in their study. The respondents who stayed in air-conditioned rooms prior to the survey had a slightly higher TSV than those who were not, suggesting the latter group were more tolerant to the heat stress in outdoor spaces. Nikolopoulou and Steemers (2003) have done a comprehensive study on psychological factors that affect thermal sensation considering naturalness, past experience, perceived control, time of exposure, environmental stimulation and expectations. For the purpose of this study, personal and psychological parameters are chosen in view of the socioeconomic background and cultural influences associated with the case study context.

Alongside dealing with the above parameters, this study deals with developing a thermal sensation prediction model using Ordinal Logistic Regression (OLR) techniques. Generally, empirical thermal sensation models based on actual sensation votes use multiple linear regression techniques and incorporate only meteorological parameters (Andrade et al. 2011; Metje et al. 2008; Nikolopoulou \& Lykoudis 2006; Nikolopoulou et al. 2003 and Ghali et al. 2011). Recent studies by Pantavou et al. (2013) suggest that OLR is a better alternative to the linear regression model in outdoor thermal comfort studies. Here, the dependent variable, TSV, is an ordinal variable based on the ASHRAE seven-point scale ( -3 cold; -2 cool; -1 slightly cool; 0 neutral; + 1 slightly warm; + 2 warm; + 3 hot) (ANSI/ASHRAE Standard 55. 2004). This indicates, it may be unsuitable to apply a linear regression model to predict thermal sensations, since multiple linear regression is mainly applicable when the dependent variable is continuous. Therefore, OLR techniques are applied in this study and the outcome is compared with the actual TSV collected through the field survey.

\section{Methodology}

\section{Study area}

A questionnaire survey was carried out along with physical measurements in the tropical megacity of Dhaka. Eight urban canyons in six representative case study areas were chosen for 
the study. These included four residential case study areas called South Kafrul, Mid-Kafrul, Mahakhali DOHS and Baridhara DOHS; one commercial area called Banani Commercial Area and one educational area called TSC Shahbagh (see Fig. 1 in the supplementary material for an overview of the case study areas).

\section{Microclimatic measurements}

The measured climatic parameters include air temperature, humidity, wind speed and globe temperature. Instruments were placed at the height of $1.1 \mathrm{~m}$ from the ground with the aid of a tripod. The height corresponds to the average height of the centre of gravity of the human body (ISO 7726 1998). The instruments consisted of Tiny-tag data loggers to measure air temperature and humidity, an OM-CP-WIND101A data logger with a three-cup anemometer to measure wind speed and a globe thermometer to measure globe temperature. The globe thermometer used a Tiny-tag data logger with a thermocouple thermistor probe inserted into a grey Ping-Pong ball $(40 \mathrm{~mm}$ diameter). Mean radiant temperature was calculated using the method described in Thorsson et al. (2007). Measurements were taken between 9:00 and 18:00.

\section{Questionnaire survey}

The survey includes 1302 interviews conducted across the case study areas. The analysis of the questionnaire data lead to two main outcomes: firstly, understanding how thermal comfort sensation is affected by climatic, personal, psychological and additional variables for the climatic context of Dhaka; and secondly, providing a predictive thermal comfort model for the case study areas. The questionnaire was prepared on the basis of previous research ( $\mathrm{Ng} \&$ Cheng 2012; Yang et al. 2013). Participants were selected at random. They were asked about their thermal sensation, acceptability and preferences along with humidity, wind speed and solar radiation sensations. Physical attributes like age, gender, and activity were noted. Body type (normal/ obese/ skinny) and clothing information were obtained from observation.

Interviewees were asked to express their thermal sensation based on the ASHRAE seven-point scale representing the TSV. Their thermal preference was noted on a three-point McIntyre Scale (prefer warmer, prefer no change, prefer cooler) (McIntyre 1980). Thermal acceptability was assessed by asking whether the thermal environment was acceptable or unacceptable. Humidity, wind speed and solar radiation sensations were recorded on individual five-point scales $(\mathrm{Ng} \&$ Cheng 2012).

The rest of the questionnaire consisted of questions to determine the most important personal and psychological attributes that affected thermal comfort sensations. These parameters, along with meteorological ones used for this study, are listed in Table 1. It also includes additional parameters discussed under 'adaptive behaviour' and 'weather opinion'. Personal information of the respondents, such as gender, age, body type, activity, exposure to direct sunlight and clothing level were also included in the table. These were determined by observation during the survey. Several personal characteristics were noted by directly asking the respondents about their residence status in the city, nature of their profession, interviewees' sweat-levels (Ng \& Cheng 2012), exposure to air-conditioned space and travelling situations in the last $30 \mathrm{~min}$, etc. Profession is grouped as "indoor type", who work in an indoors environment and "outdoor type", who work mostly outdoors (e.g. street traders) (Ahmed 2003). Respondents' psychological factors included visiting purposes to the site and whether the next destination is air conditioned or not. Choice of adaptive behaviour, consumption of hot food or cold drinks, etc. were considered under 'adaptive behaviour'. Additionally, interviewees' judgement of the prevailing humidity, wind speed and solar radiation conditions during the survey were recorded. The reason for considering the 'visiting purpose' and 'next destination is air conditioned' under the psychological category is that both have considerable psychological impact on the respondent's mental situation. Visiting a place for leisure could have a different psychological effect to someone who is present for work. Pantavou and Lykoudis (2014) and Pantavou et al. (2013) have shown in their studies that people visiting the site for work felt cooler than those visiting the site for rest, due to both psychological effects and also because the former group had better adaptation due to longer exposure time than those simply passing by. Similarly, people whose next destination is air-conditioned could be more tolerant to warm situations as they know any discomfort is temporary. Regarding 'weather opinion', although Pantavou et al. (2013) have discussed this under psychological parameters, it is discussed separately in this study as these can be broadly treated as comparable to the ASHRAE TSV. This is similarly applicable in the case of adaptive behaviour.

\section{Regression analysis}

This study has applied OLR techniques, for predicting TSV in the case study context, in three stages: first, using only meteorological variables to produce a meteorological model; second, combining personal variables with meteorological variables to produce a thermo-physiological model; third, incorporating 'Weather opinion' with personal and meteorological variables to produce a combined parameter model. While producing the models, each independent variable is examined against TSV separately. The impact of each continuous, as well as categorical, variable on the dependent variable TSV is individually checked beforehand, using the one-way ANOVA, Kruskal-Wallis and Mann-Whitney tests. All statistical analysis in this study has been carried out in ' $R$ ' programming language (https://www.r-project.org/). 
Table 1 Meteorological, personal, psychological and additional parameters in the study

\begin{tabular}{|c|c|c|c|c|}
\hline \multirow{2}{*}{$\begin{array}{l}\text { Measured parameters } \\
\text { Meteorological }\end{array}$} & \multicolumn{4}{|l|}{ Questionnaire parameters } \\
\hline & Personal & Psychological & Adaptive behaviour & Weather opinion \\
\hline Air temperature, $\mathrm{Ta}\left({ }^{\circ} \mathrm{C}\right)$ & Gender & Visiting purpose & Cold drink in the last $15 \mathrm{~min}$ & Humidity sensation \\
\hline Relative humidity, RH (\%) & Age & $\begin{array}{l}\text { Next destination is } \\
\text { air-conditioned }\end{array}$ & Hot food in the last $15 \mathrm{~min}$ & Wind speed sensation \\
\hline Wind speed (m/s) & Body type & & Preferred adaptive behaviour & $\begin{array}{l}\text { Solar radiation } \\
\text { sensation }\end{array}$ \\
\hline Globe temperature, GT $\left({ }^{\circ} \mathrm{C}\right)$ & Activity, metabolic rate $\left(\mathrm{W} / \mathrm{m}^{2}\right)$ & & & \\
\hline \multirow[t]{7}{*}{ Mean radiant temperature, $\operatorname{Tmrt}\left({ }^{\circ} \mathrm{C}\right)$} & Body exposure to the sun & & & \\
\hline & Clothing, Clo & & & \\
\hline & Time living in Dhaka & & & \\
\hline & $\begin{array}{l}\text { Profession-type (outdoor or } \\
\text { indoor) }\end{array}$ & & & \\
\hline & $\begin{array}{l}\text { Exposure to air-conditioned space } \\
\text { in the last } 30 \mathrm{~min}\end{array}$ & & & \\
\hline & Travelling in the last $30 \mathrm{~min}$ & & & \\
\hline & Sweat-levels & & & \\
\hline
\end{tabular}

The OLR applied in this study is used to model the relationship of an ordinal dependent variable and a set of independent variables that are either categorical or continuous. In an OLR model, the outcome variable is ordered and has more than two levels. The distance between the levels is generally unknown (Christensen 2011). In this study, the ordinal outcome variable is TSV, which is coded on the seven-point scale. Please see the discussion on OLR in the supplementary document for further information.

\section{Results and discussion}

\section{Thermal sensation and meteorological variables}

During the questionnaire survey, air temperature ranged between 27.6 and $38.5^{\circ} \mathrm{C}$, relative humidity between 51 and $85 \%$, globe temperature between 27.9 and $42.9{ }^{\circ} \mathrm{C}$ and Tmrt between 27.7 and $47.8{ }^{\circ} \mathrm{C}$. Wind speed remained generally low $($ mean $=0.9 \mathrm{~m} / \mathrm{s})$. However, some gusts were recorded in the traditional areas with greater building height variation and in the commercial area with high-rise structures, especially where funnelling effect was noted. According to the data collected from the Bangladesh Meteorological Department at Dhaka, the survey days can be regarded as typical days when the high temperature is coupled with high humidity, having average cloud coverage of 5.5 oktas.

\section{Questionnaire data}

The survey was conducted for 12 days, of which 6 days were in Autumn 2014 and 5 days were in Summer 2015. Around
$42 \%$ of the data was collected in Autumn and the remaining $58 \%$ during Summer. The descriptive statistics of the population has been included in Table 1 in the supplementary material. Out of 1302 respondents, 76\% were male. Ninety-one percent of respondents consisted of people aged between 16-30 and 30-50. The most common physical feature (termed as 'body type') was 'normal'. Considering this study examines outdoor comfort conditions, different activities that take place in the outdoor urban environment were considered. The majority of the respondents (49\%) were standing or involved in light work, and the second largest group of people $(37 \%)$ were walking at a slow pace (light walking).

During the questionnaire survey, $92 \%$ of people were walking in the shaded part of the street and therefore not exposed to direct sun. Clothing values were estimated by observation and compared to the garment checklist included in the questionnaire. The mean and median values for clothing were both 0.5 clo, which is normal considering the thermal conditions during the survey. Maximum values were around $1.2 \mathrm{clo}$, as some women were dressed in the Islamic manner. People's acclimatisation was also considered, and $76 \%$ were a resident of the city for over 5 years. Respondents were also asked about their profession. The highest percentage (37\%) was involved in office jobs and $31 \%$ were students. Among these people, $73 \%$ of jobs were indoor-based, while $26 \%$ were outdoor-based.

It can be assumed that respondents were already acclimatised during the survey with the thermal environment as $71 \%$ had not had any exposure to air-conditioned space in the last $30 \mathrm{~min}$. Furthermore, $79 \%$ were not travelling before the interview, while $21 \%$ were either on public transport or another type of transport. The largest percentage (80\%) was at the 
interview site due to proximity to home, office, school or transport node.

Approximately, $34.4 \%$ of the respondents felt 'Slightly Warm' during the overall survey period (Fig. 1a). With weather conditions during the survey period significantly above the comfort level and air temperature conditions ranging between 27.6 and $38.5^{\circ} \mathrm{C}$ (average $31.8^{\circ} \mathrm{C}$ ), less than one fifth of the population (14.8\%) reported feeling 'Neutral' and 28 and $21.4 \%$ feeling 'Warm' and 'Hot', respectively. TSV during autumn 2014 was quite different from TSV in summer 2015, especially the percentage of people feeling 'Hot' is significantly higher in summer 2015 (Fig. 1b, c). Although the study uses the ASHRAE seven-point thermal sensation scale, 'Cool' and 'Cold' categories are not presented in the figures as there was no response in these categories during the survey.

\section{Analysis of the relationship between TSV and independent variables}

\section{One-way ANOVA analysis}

In order to define the relationship between TSV and climatic variables, analysis of variance was applied. One-way (one predictor variable) analysis of variance revealed statistically significant differences between the classes of TSV and all meteorological parameters (Fig. 2a-e). From the mean Ta, people's neutral comfort range is $30.7{ }^{\circ} \mathrm{C} \pm 1.26$. Figure $2 \mathrm{a}$ shows the boxplots of outdoor air temperature against TSV for the survey period. The trend between outdoor temperature and TSV shows a higher TSV is associated with higher outdoor temperature. A similar trend is visible between TSV and globe temperature and TSV and mean radiant temperature Relative humidity shows a negative effect on TSV similar to Pantavou and Lykoudis (2014) and Givoni et al. (2003). The trend between TSV and wind speed are similar to the above trend. As wind speed reduces, TSV increases.

\section{Analysing thermal sensation and categorical variable}

The aim of this section is to statistically test if there is a significant difference between the thermal sensation depending on the personal parameters. A percentage distribution of the personal parameters (nominal variables) as per ordinal ranking of TSV (ordinal variable) is presented in the bar plots (Fig. 3a-i). A Mann-Whitney test (for two values in a nominal variable) and a Kruskal-Wallis test (for more than two values in a nominal variable) were applied. These non-parametric tests are applied when there is one nominal variable and one ranked variable. They test whether the mean ranks are the same in all the groups. The null hypothesis of the Kruskal-Wallis test is that the mean ranks of the groups are the same. When the null hypothesis is true, we can decide that the nominal variable has no impact on the ordinal variable. If the $p$ value is greater than 0.05 , we need to accept the null hypothesis as true. The nonparametric test results between TSV (ordinal variable) and personal parameters can be found in Table 2 .

To examine the impact of 'Clothing', a one-way ANOVA analysis was carried out, considering 'Clothing' as a continuous variable. No significant impact on TSV was found, as the 'Clothing' value for most people were around 0.5 Clo.

It was examined whether there is a significant difference between TSV concerning gender. Pantavou et al. (2013) have found a higher percentage of males feeling 'Neutral' than females and a higher percentage of females in the extreme categories ( +3 and -3 ), indicating that females are more vulnerable to thermal conditions (Schellen et al. 2012; Krüger \& Rossi 2011; Karjalainen 2007). From the bar plot (Fig. 3a), the highest percentage of males falls in the +1 category, while the highest percentage of females falls in the +2 category. From the Mann-Whitney test, we can reject the null hypothesis that males and females have the same TSV ranking at the 5\% level (Table 2). That means the finding of this research a

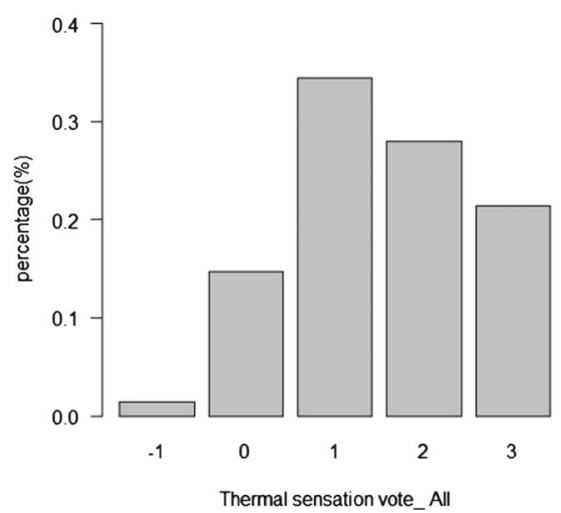

b

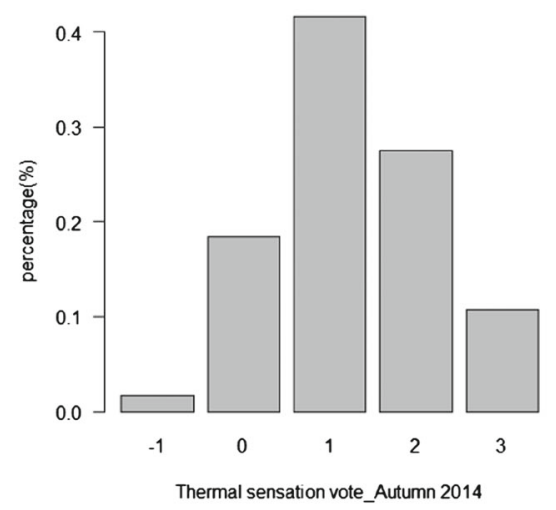

C

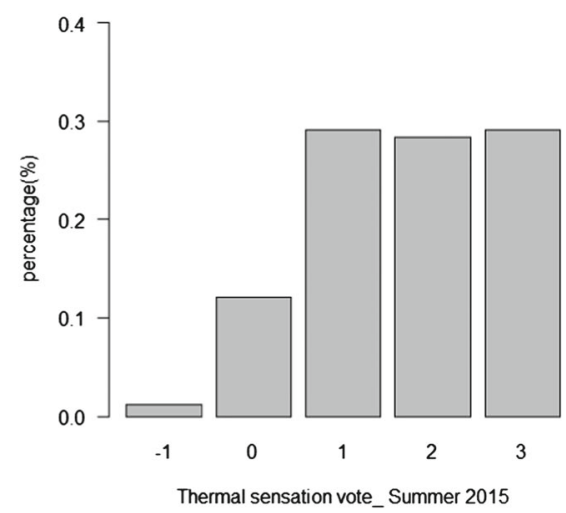

Fig. 1 Histogram of TSV: a. TSV_All, b. TSV_Autumn 2014, c. TSV_Summer 2015 


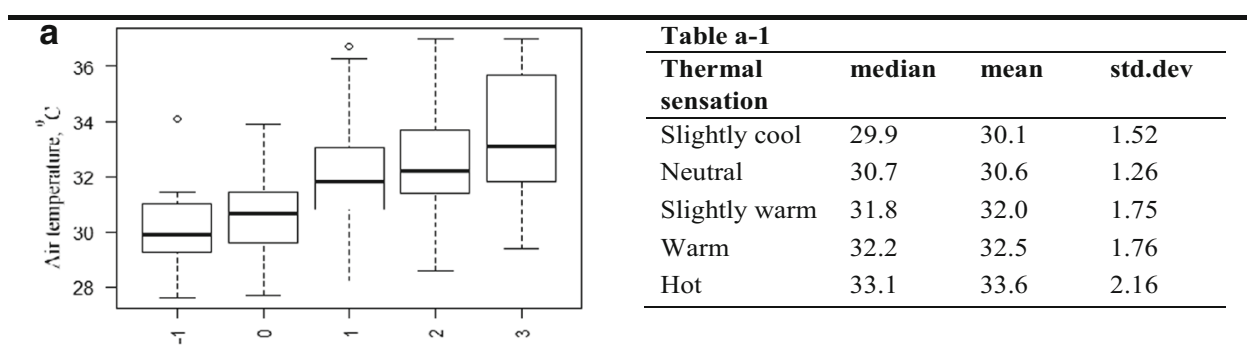

TSV

Air temperature $\sim$ Thermal sensation

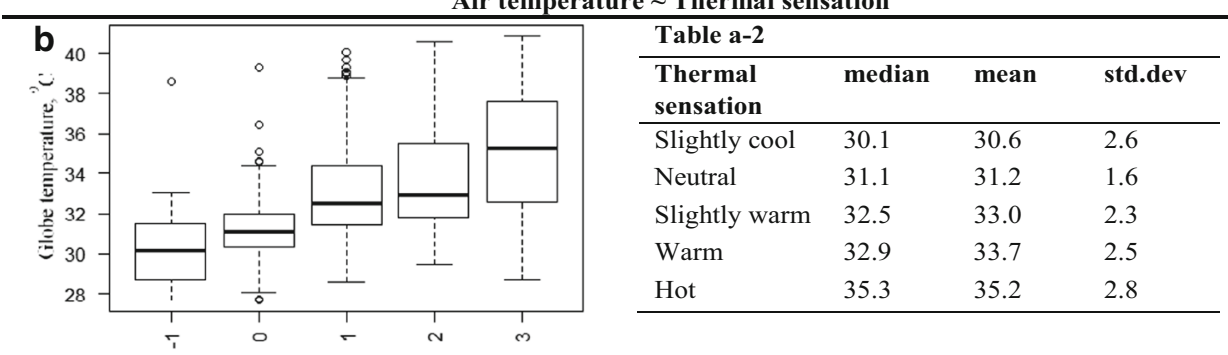

Globe temperature $\sim$ Thermal sensation

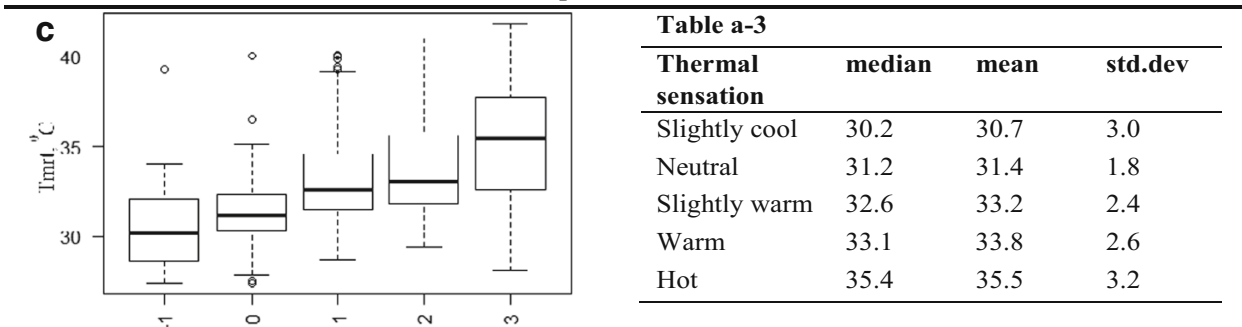

TSV

Tmrt $\sim$ Thermal sensation

\begin{tabular}{l|l|l|llll}
\hline $\mathbf{d}$ \\
\hline
\end{tabular}

TSV

Relative humidity $\sim$ Thermal sensation

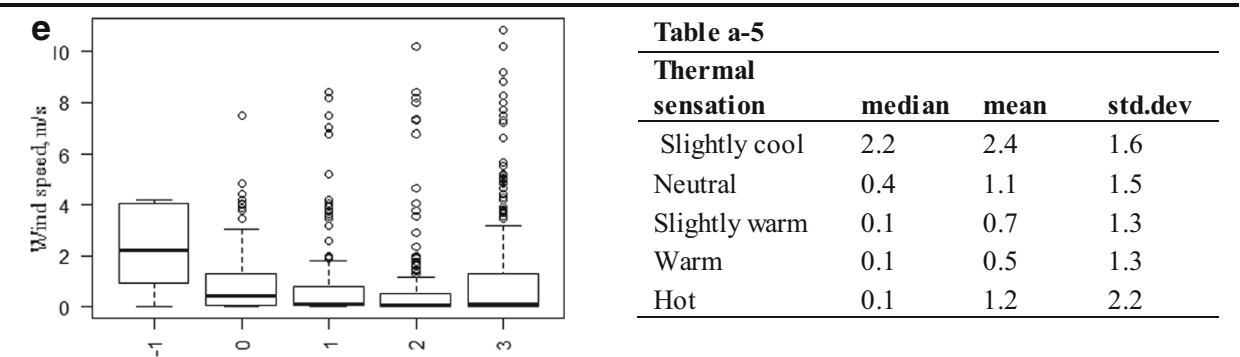

Wind speed $\sim$ Thermal sensation

Fig. 2 Results of one-way analysis of variance between TSV and climatic variables: a. Table a-1: air temperature against TSV, b. Table a-2: globe temperature against TSV, c. Table a-3 Tmrt against TSV, d. Table a-4 relative humidity against TSV, e. Table a-5 wind speed against TSV box-plot and table 
Fig. 3 Personal, adaptive, psychological and weather sensation parameters per class of TSV: a. Gender, b. Age, c.

Activity, d. Body exposure, e.

Profession type, f. Exposure to air-conditioned space, g. Sweat levels, h. Next destination is airconditioned, i. Cold food in 15 minutes, $\mathrm{j}$. Reason for visiting the place, k. Chosen adaptive behaviour, 1 . Humidity sensation, $m$. Wind speed sensation, $n$. Solar radiation sensation per category of TSV a

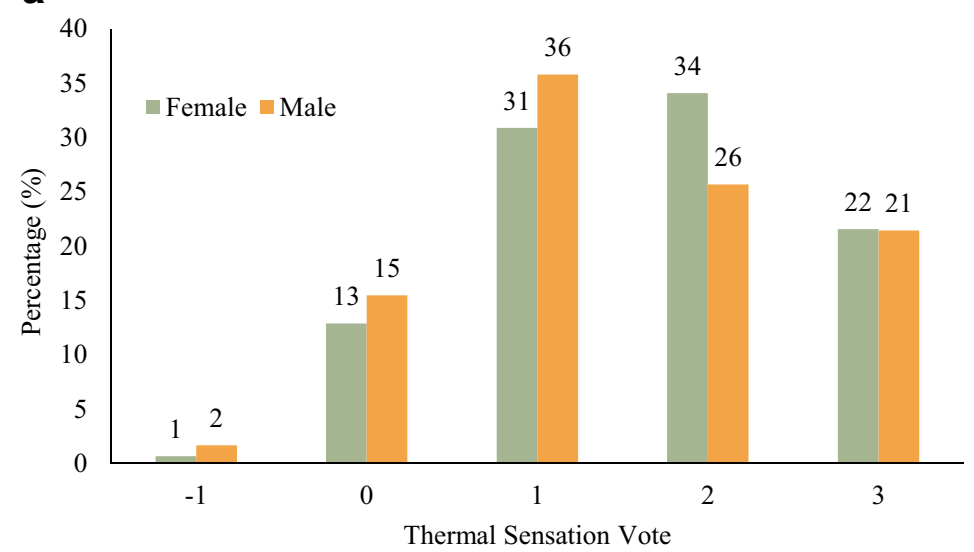

b

Gender per category of TSV

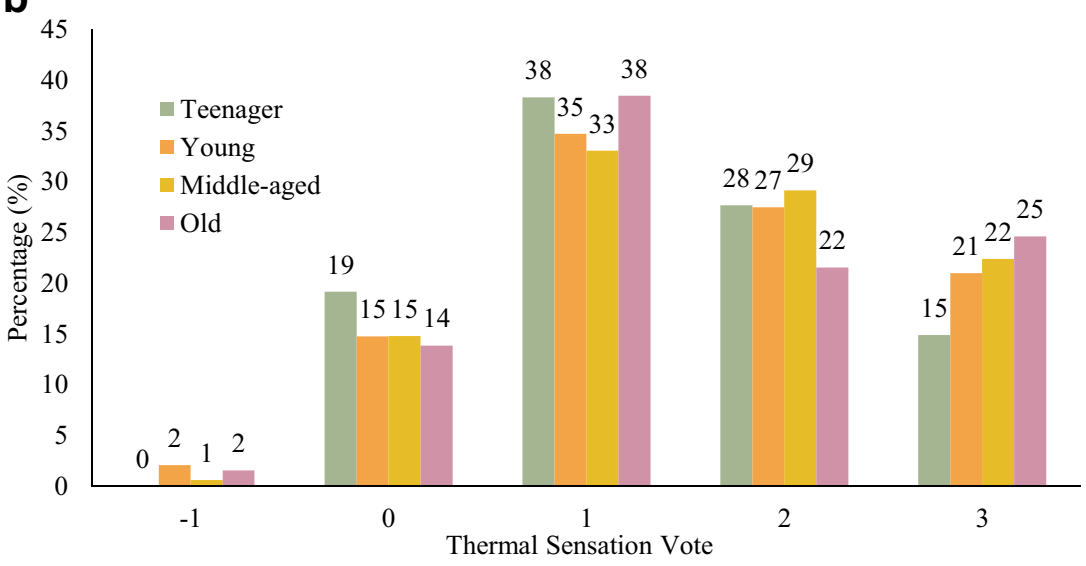

Age per category of TSV

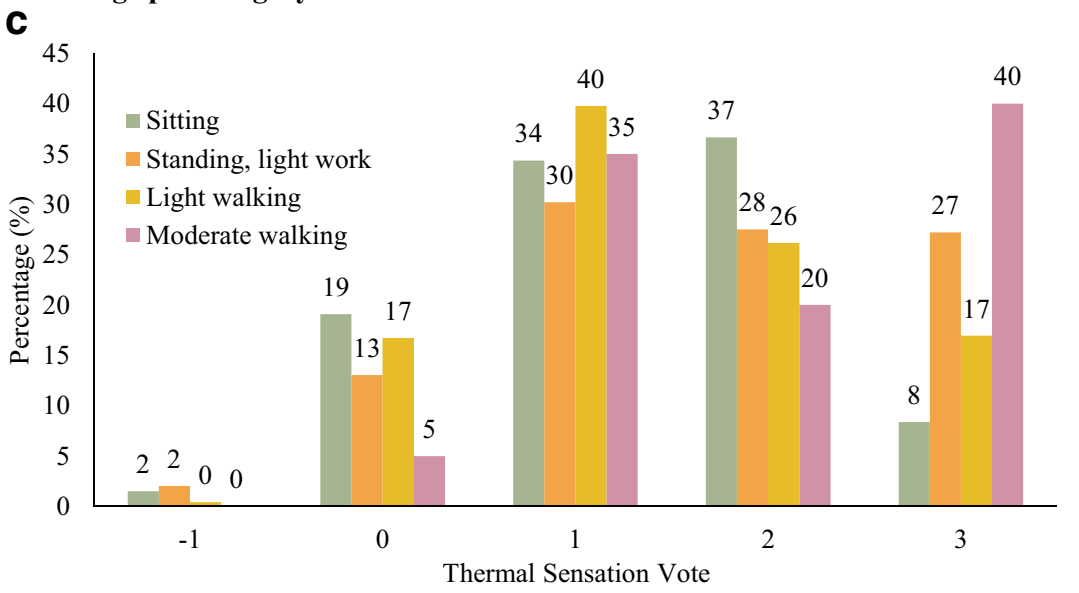

Activity per category of TSV agrees with the finding of the previous research that women are more vulnerable to heat than men.

Regarding age, Pantavou et al. (2013) have noticed increased sensitivity to heat among older people, although Krüger and Rossi (2011) found an opposite trend. In Fig. 3b, there is seemingly no difference between people of different ages for different groups of TSV rankings.
Considering the 'Activity' of the respondents, those involved in 'Light walking' or 'Standing, light work' show similar patterns where the majority fall in the +1 category and the next group in the +2 category (Fig. 3c). Majority of the respondents who were in 'Moderate walking' group, fall in the +2 category. Their higher metabolism makes them feel hotter. Most of the people who are in neutral category are found 'Sitting'. Thus, the 

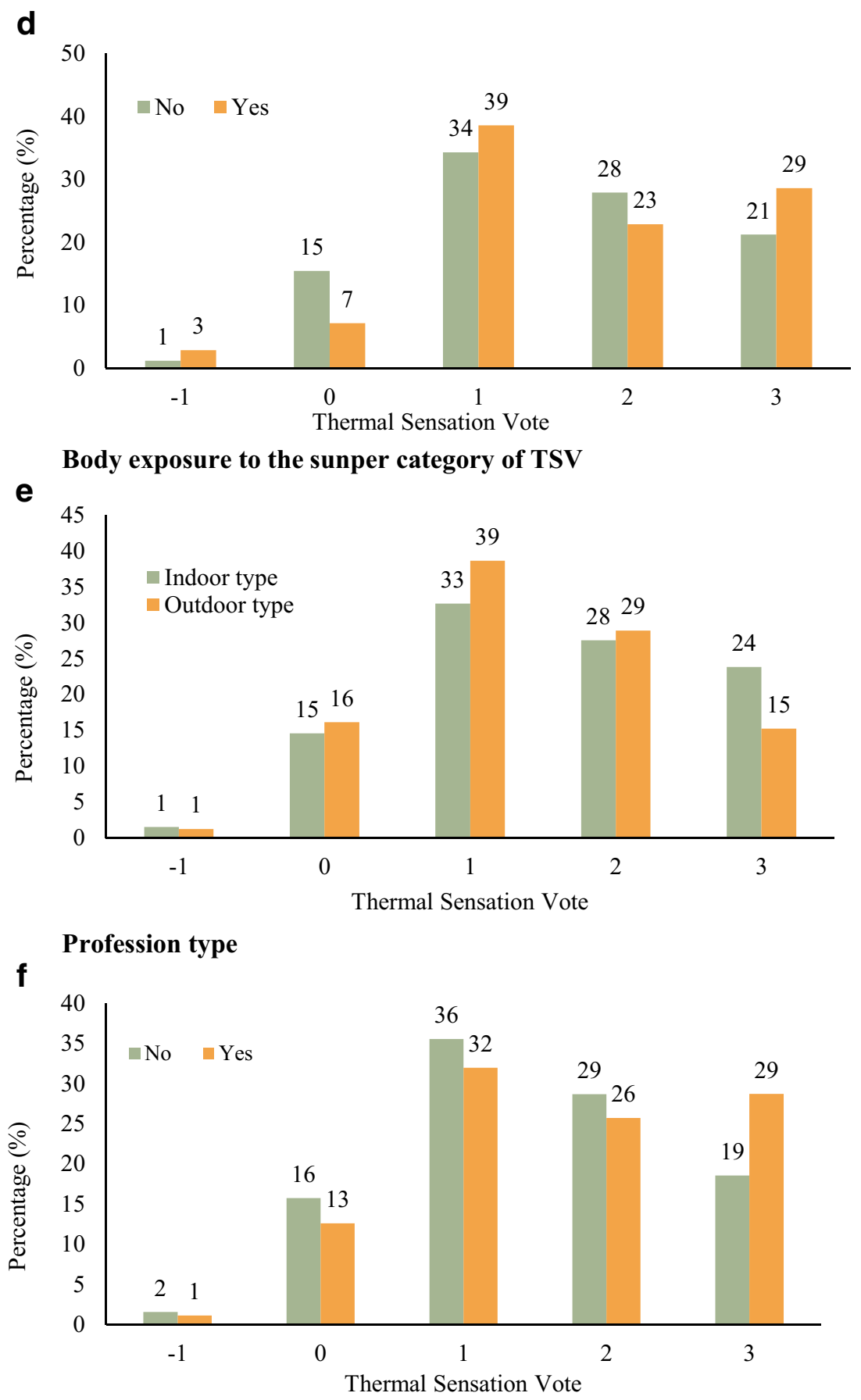

Exposure to air-conditioned space per category of TSV

Fig. 3 continued.

difference in TSV between the groups is evident as TSV seems to increase with the increase of activity levels. This means activity levels have a statistically significant impact on TSV.

In terms of 'Profession type', people who are 'Indoor-type' (involved in indoor-based work) have $9 \%$ higher percentage in the category +3 than people who are 'Outdoor type' (Fig. 3e). Also, the percentage of the former group in the ' 0 ' and +1 categories is $7 \%$ higher than the latter. This suggests 'Indoor- type' people are more sensitive to hot situations. Also, people who had exposure to air-conditioned space prior to the survey, have $10 \%$ higher percentage in the +3 category than those who did not (Fig. 3f). This suggests air-conditioning experience have led people to feel hotter in outdoor spaces similar to the findings reported in Yang et al. (2013) as discussed before. Those who did not have any air-conditioning experience have $7 \%$ higher percentage in the ' 0 ' and +1 categories than the 

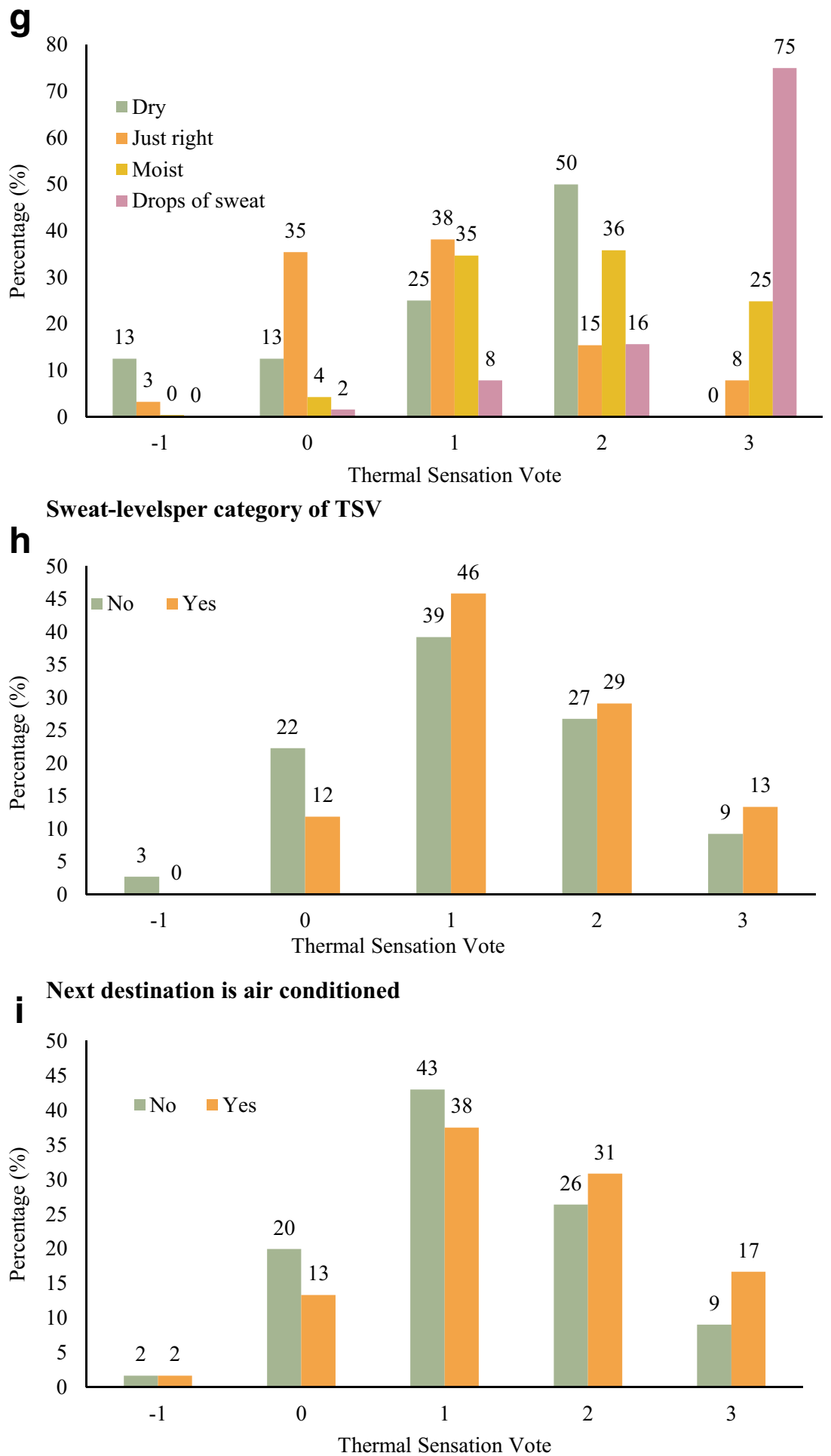

Cold food in 15 minutes

Fig. 3 continued.

other group. The respective Mann-Whitney tests as presented in Table 2 support these findings.

'Sweat-levels' has been examined in this study to understand the thermal sensation of people. From the barplot in Fig. 3g, people feeling 'Just right' in terms of 'Sweat-levels' mostly belong to the
' 0 ' or +1 category. On the other hand, people who felt 'Moist' fall in the $+1,+2$ and +3 categories. Similarly, people experiencing 'Drops of sweat' feel mostly 'Hot'. However, it is not clear why $50 \%$ of the people feeling 'Dry' fall in the +2 category. It was anticipated that people feeling 'Warm' would link their thermal 

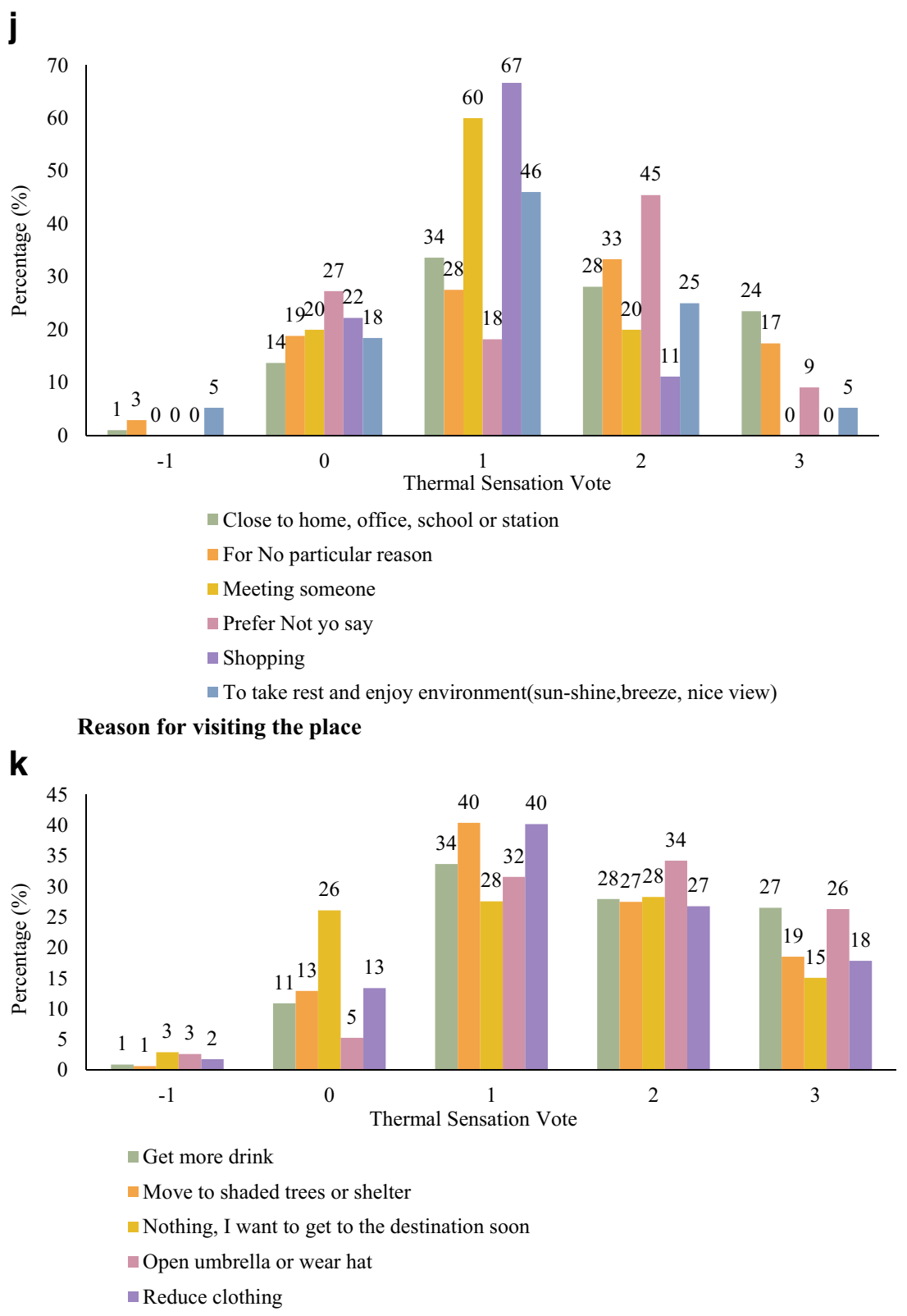

Chosen adaptive behaviour

Fig. 3 continued.

sensation with 'Moist' or 'Drops of sweat' conditions. Seemingly, some people got confused in distinguishing between 'Dry' and 'Moist'. However, the Kruskal-Wallis test suggests that there is a difference in TSV level among people with different groups of 'Sweat-levels'.

Other parameters, such as 'Body type', 'Body exposure to sun' (Fig. 3d), 'Time living in Dhaka', 'Travelling in last_30 min' and 'Hot food in last 15 min' did not have any statistically significant impact on the respective levels for the different categories of TSV. The reason why 'body type' did not have any impact could be that most people $(76 \%)$ had 'Normal' body type. 'Body exposure to sun' (Fig. 3d), 'Time living in Dhaka' and 'Travelling in last $30 \mathrm{~min}$ ' did not have an impact for similar reasons relating to survey population as $92 \%$ of the people did not have solar exposure, $76 \%$ have lived in the city for over 5 years and $79 \%$ were not travelling in the last $30 \mathrm{~min}$. The effect of 'Hot food' could only be speculated as not having a lasting effect after $15 \mathrm{~min}$ or more prior to the survey.

It was initially assumed that people whose next destination was air-conditioned will be more tolerant (and psychologically convinced) towards the temporary discomfort in hot outdoor conditions. Although most people in both groups fall in the +1 category, those with air-conditioned destinations are 7 , 2 and $4 \%$ higher in the $+1,+2$ and +3 categories respectively, showing more dissatisfaction with existing conditions (Fig. 3h). Conversely, people without an air-conditioned 

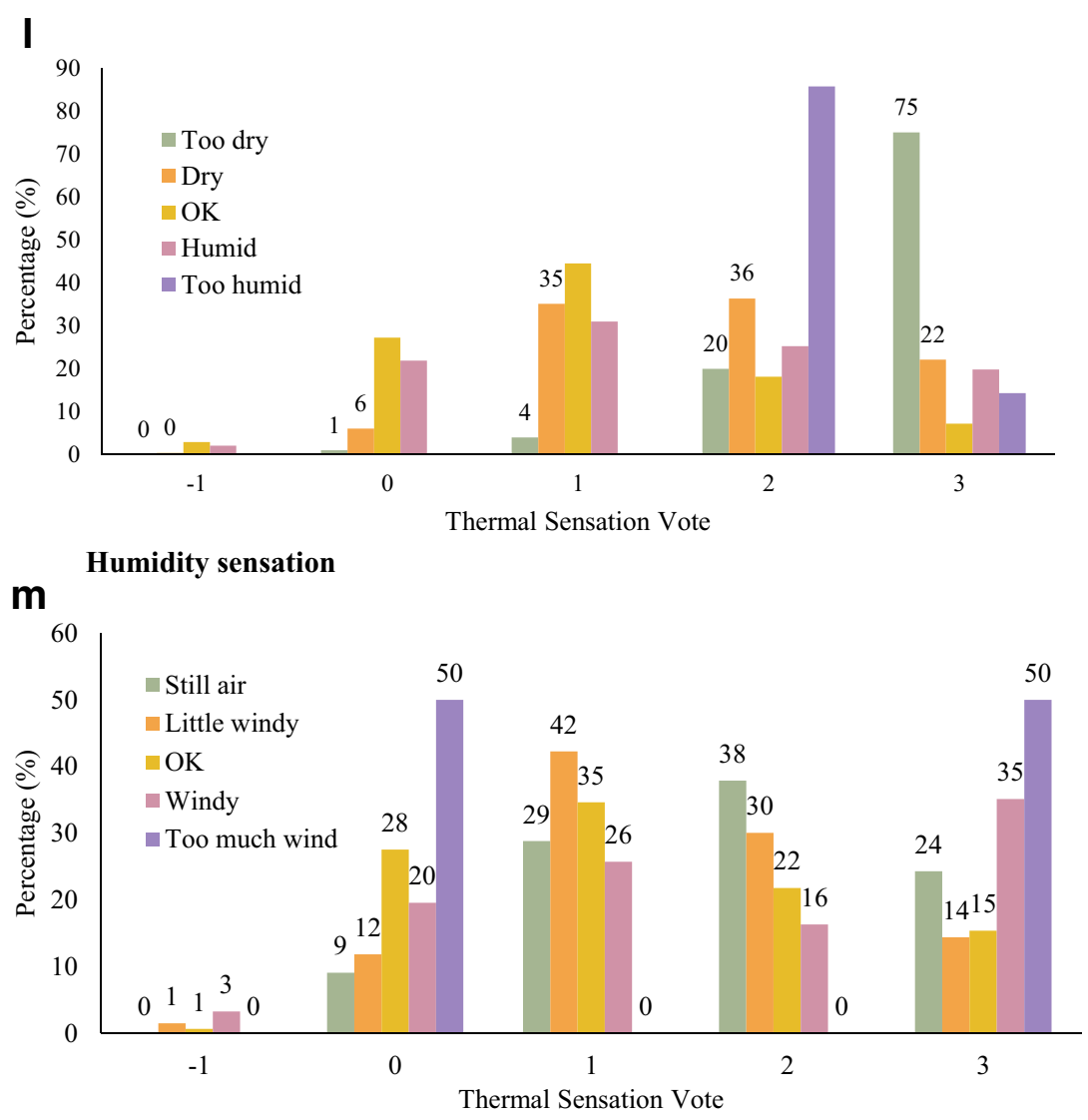

Wind speed sensation

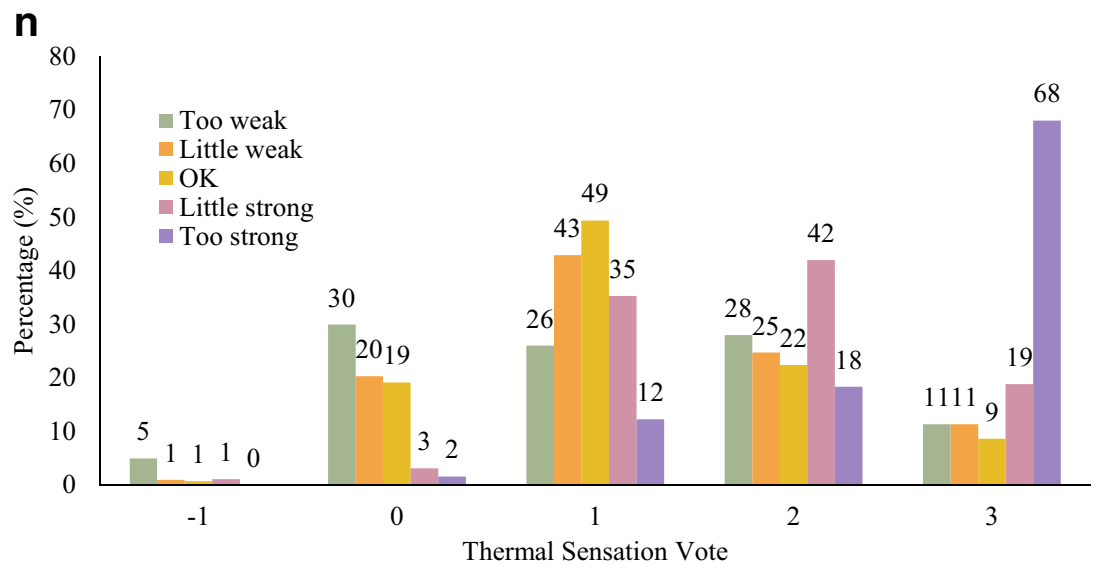

Solar radiation sensation

Fig. 3 continued.

destination have a $10 \%$ higher percentage in the 'Neutral' category, showing they are more tolerant towards the prevailing situation. There could be various reasons for that: the anticipation of comfort made them more aware of current discomfort, the destination is far away, they were getting late, etc. The Mann-Whitney test (Table 2) confirms the negative effect of air-conditioned destination on TSV levels.

Next, the consumption of cold food or drink (Fig. 3i) also seemed to have an impact on the thermal sensation, although in an opposite way as the Mann-Whitney test (Table 2) suggests. Consumption of cold food or drink did not seem to have lowered the thermal sensation of people as it shows 5 and $8 \%$ higher percentage of people in the +2 and +3 categories, respectively. The reason could be that the thermal sensations of these people were affected by other factors which exceeded the effect of cold food or drink. Or maybe, considering the hot-humid conditions during the survey period, the effect of the cold food or drink did not last for $15 \mathrm{~min}$. Since past activities of the respondents could not be monitored, it is difficult to assume. 
Table 2 Non-parametric test results between TSV and personal, psychological and additional parameters

\begin{tabular}{|c|c|c|c|c|c|}
\hline Variables & Test name & W (Mann-Whitney test) & Kruskal-Wallis chi-squared & $p$ value & Null hypothesis \\
\hline TSV by Gender & Mann-Whitney & $161,840.000$ & & 0.044 & Rejected \\
\hline TSV by Age & Kruskal-Wallis & & 2.341 & 0.505 & Cannot reject \\
\hline TSV by Body Type & Kruskal-Wallis & & 3.708 & 0.295 & Cannot reject \\
\hline TSV by Activity & Kruskal-Wallis & & 24.371 & 0.000 & Rejected \\
\hline TSV by Body exposure to the sun & Mann-Whitney & $38,080.000$ & & 0.2354 & Cannot reject \\
\hline TSV by Time living in Dhaka & Kruskal-Wallis & & 2.050 & 0.359 & Cannot reject \\
\hline TSV by Profession-type & Mann-Whitney & $169,250.000$ & & 0.009 & Rejected \\
\hline TSV by Exposure to air-conditioned space & Mann-Whitney & $148,860.000$ & & 0.001 & Rejected \\
\hline TSV by Travelling in last $30 \mathrm{~min}$ & Mann-Whitney & $33,401.000$ & & 0.077 & Cannot reject \\
\hline TSV by Skin wetness & Kruskal-Wallis & & 294.560 & 0.000 & Rejected \\
\hline TSV by Reason for visiting the place & Kruskal-Wallis & & 27.35 & 0.000 & Rejected \\
\hline TSV by Chosen adaptive behaviour & Kruskal-Wallis & & 30.63 & 0.000 & Rejected \\
\hline TSV by Next destination air-conditioned & Mann-Whitney & $29,266.000$ & & 0.003 & Rejected \\
\hline TSV by Cold food in last $15 \mathrm{~min}$ & Mann-Whitney & $21,404.000$ & & 0.007 & Rejected \\
\hline TSV by Rich food in last $15 \mathrm{~min}$ & Mann-Whitney & $22,150.000$ & & 0.860 & Cannot reject \\
\hline TSV by Humidity sensation & Kruskal-Wallis & & 259.77 & 0.007 & Rejected \\
\hline TSV by Wind speed sensation & Kruskal-Wallis & & 37.218 & 0.000 & Rejected \\
\hline TSV by Solar radiation sensation & Kruskal-Wallis & & 279.52 & 0.000 & Rejected \\
\hline
\end{tabular}

Eighty percent of the survey population claimed to be in the sites because of closeness to home, office, school or transport node (see Table 1 in the supplementary material). Overall, the reason for visiting the place (also including meeting someone, shopping, to take rest and enjoy environment, etc.) had a statistically significant impact on the TSV levels as can be seen from the Kruskal-Wallis test on Table 2 and Fig. 3j. Similarly, people at the different TSV levels expressed different preferences for adaptive behaviour (Fig. 3k). For example, people in the 'Neutral' category mostly $(28 \%)$ did not choose an adaptive behaviour; they were happy to continue to their destination. Most people $(80 \%)$ in the 'Slightly warm' category showed preferences for moving under shaded trees or shelter $(40 \%)$ and reducing clothing (40\%). People feeling 'Warm' and 'Hot' were preferred to open an umbrella or wear a hat (26-34\%) or get more drink (27-28\%).

Regarding humidity sensation, most people feeling 'Neutral' or 'Slightly warm' found the humidity conditions to be 'OK' and people feeling 'Warm' have associated it to be 'Too humid' (Fig. 31). However, 75\% of people feeling 'Too dry' fall under the +3 category. This is slightly unusual because in an already humid condition, feeling worse should be associated with more humid rather than drier conditions. Therefore, it seems that respondents feeling 'Too dry' (7\% of the population) were not fully able to evaluate the humidity conditions. Pantavou et al. (2013) in a similar study have revealed that people have "doubtful perception of relative humidity". In other words, there is seemingly a difference between how people perceive humidity from the actual humidity levels. Results from Villadiego and Velay-Dabat (2014) also indicated that survey-respondents did not clearly notice the role that humidity plays in their thermal sensation.

It is hard to tell the effect of wind from Fig. $3 \mathrm{~m}$ given the amount of variations (as indicated in the number of outliers in Fig. 2) and the fact that there were very low levels of prevailing wind during the measurement campaign. In Fig. 3n, most people who were in the 'Slightly warm' category identified solar radiation to be 'OK', while people in the 'Hot' category responded 'Too strong'. People who felt solar radiation to be 'Too weak' fell in the ' -1 ' or ' 0 ' category and people who felt it to be 'Little strong' were in the +2 category. Overall, all humidity, wind speed and solar radiation sensation levels varied for different categories of thermal sensations. Kruskal-Wallis tests for each of these parameters show statistically significant results (Table 2) and therefore their impact on thermal sensation levels is confirmed.

\section{Prediction of TSV}

\section{Prediction of TSV using OLR}

This section of the study is carried out with the aim to develop predictive thermal comfort models for the case study area. OLR is applied for three different sets of parameters: meteorological, thermo-physiological and a combination of thermo-physiological and weather opinion factors. Application of OLR to the meteorological parameters 
yielded sets of equations for calculating cumulative probabilities (Eq. (1)). Instead of considering the probability of an individual event, the probability of that event and all events that are ordered before it is considered in the case of cumulative probabilities. The probability of each individual category can be computed by subtracting the higher corresponding class from the lower one.

$$
\begin{aligned}
& P(\leq-1)=\left\{1+\exp \left[-\left(10.2538-\left(0.317^{*} \text { Ta }+0.1426^{*} \text { Tmrt }-0.1565^{*} \text { Windspeedsqrt }\right)\right)\right]\right\}^{-1} \\
& P(\leq 0)=\left\{1+\exp \left[-\left(12.9702-\left(0.317^{*} \text { Ta }+0.1426^{*} \text { Tmrt }-0.1565^{*} \text { Windspeedsqrt }\right)\right)\right]\right\}{ }^{1} \\
& P(\leq 1)=\left\{1+\exp \left[-\left(14.9472-\left(0.317^{*} \text { Ta }+0.1426^{*} \text { Tmrt }-0.1565^{*} \text { Windspeedsqrt }\right)\right)\right]\right\}-{ }^{1} \\
& P(\leq 2)=\left\{1+\exp \left[-\left(16.4530-\left(0.317^{*} \text { Ta }+0.1426^{*} \text { Tmrt }-0.1565^{*} \text { Windspeedsqrt }\right)\right)\right]\right\}-^{1} \\
& P(\leq 3)=1
\end{aligned}
$$

The ordinal meteorological models are produced by multiple meteorological variables, air temperature, Tmrt and windspeedsqrt. The coefficients and standard errors can be found in Table 3a. The intercepts in each set of equations vary as can be seen in Eq. (1). The coefficients for meteorological variables are identical. The model was tested for the proportional odds assumption and ordinal regression was applied as the assumption was satisfied in all three ordinal models. The odds ratio, that is simply the inverse log (i.e. the exponential) of the estimated coefficient, can be read from Table 3. The interpretation of the odds ratio is that, for a one-unit change in the predictor variable, the odds for cases in a group that is greater than $\mathrm{j}$ versus less than or equal to $\mathrm{j}$ are the proportional odds times larger. For example, when air temperature moves 1 unit, the odds of TSV being in the 'Hot' category are 1.373 times greater than TSV being in 'Warm' and lower category.

In order to test the correspondence between actual TSV and the respective predicted votes in the meteorological model, the latter were classified into five categories using simple rounding to the nearest integer as only five categories were identified during the field survey ('Slightly cool', 'Neutral', 'Slightly warm', 'Warm' and 'Hot'). The cross-tabulation of actual TSV and TSV predicted meteorological model (Fig. 4a) shows that the model predicted thermal sensation in four categories that exclude 'Slightly cool'. $71.3 \%$ of 'Slightly warm' and $47.1 \%$ of 'Hot' were correctly predicted by the model. However, reduced predictability is seen in other categories: 'Neutral' (9.6\%) and 'Slightly warm' (17.8\%). A Pseudo $R^{2}$ value of 0.245 (Table 3a) indicates that meteorological variables explain $24.5 \%$ of the comfort sensation of the pedestrians.

Next, an ordinal thermo-physiological model was created by using both meteorological and personal parameters. Among statistically significant personal parameters, 'Gender', 'Profession-type' and 'Cold food' were not included in the model to avoid a complex model. Kruger and Drach (2017) in their multiple regression model using anthropometric variables for estimating thermal sensation have also excluded Gender, Age and BMI (Body Mass Index) as they were not statistically significant.

Even though the 'Activity' of the respondents was found to be a significant parameter and metabolic heat production is an established parameter in the heat balance equation (Katavoutas et al. 2009; Fanger 1970), it was not included in the model, since the focus of this study is on pedestrian comfort where the difference of metabolic rate was little (Pantavou et al. 2013). Also, the difference of metabolic rate among the survey population was already less as only $2 \%$ of the total population were found under the category of 'Moderate walking' (see supplementary material). The other personal parameter to significantly affect thermal sensation was 'Sweatlevels' and 'Exposure to air-conditioned space'. These were incorporated along with meteorological variables to produce a thermo-physiological model. The model statistics can be found in Table 3b. The model explains $38.5 \%$ (Pseudo $R^{2}=$ 0.385 ) of the variation in TSV of the pedestrians compared to $24.5 \%$ explained by the previous metrological model.

Cross-tabulation of the model outcome compared to the actual TSV (Fig. 4b) shows that the model predicted the upper four categories of thermal sensation: namely $0,+1,+2$ and + 3. $63.9 \%$ of 'Slightly warm' category and $51.3 \%$ of 'Hot' category was correctly predicted by the model. Again, slightly lesser predictability is seen in 'Neutral' (25.4\%) and 'Slightly warm' $(20.7 \%)$ categories.

Among the psychological and additional variables, significant correlation was found between TSV and 'Reason for visiting the place', 'Chosen adaptive behaviour' and 'Next destination air-conditioned' (Table 2). However, the psychological parameters were not included in the model as they are very subjective. Weather opinions have significant correlations. Again, in order produce a simple model, only solar radiation sensation (SSV) is incorporated into the model as it had the highest correlation with TSV than other weather opinions. Subsequently, the previous thermo-physiological model was combined with SSV. The combined parameter model statistics output can be found in Table 3c. Predicted values were classified in the same manner as in the previous model to compare with actual TSV using the cross-tabulation method, and the model is able to predict all four categories of interest. The model produces a gamma coefficient of 0.727 and Pseudo $R^{2}$ value of 0.456 , meaning that almost $45.6 \%$ of the variation in thermal sensation can be explained by this model.

Approximately, over one third (34.4\%) of the respondents felt 'Slightly Warm' during the overall survey period (Fig. 1a). 
Table 3 Result of ordinal regression

\begin{tabular}{|c|c|c|c|c|c|c|}
\hline Parameters & Coefficients & Standard error & \multicolumn{4}{|c|}{ Further model parameters } \\
\hline \multicolumn{7}{|c|}{ a. TSV predicted ordinal meteorological model } \\
\hline Slightly cool $=-1$ & 10.254 & 0.934 & Pseudo $R^{2}$ & 0.245 & & \\
\hline Neutral $=0$ & 12.970 & 0.919 & Gamma & 0.575 & & \\
\hline Slightly warm $=1$ & 14.947 & 0.939 & std. error & 0.029 & & \\
\hline Warm $=2$ & 16.453 & 0.958 & CI & 0.517 & 0.632 & \\
\hline Hot $=3$ & 0.000 & & cor.test & 0.417 & & \\
\hline Air temperature & 0.317 & 0.045 & Pseudo $R^{2}$ & 0.245 & & \\
\hline Tmrt & 0.143 & 0.032 & & Odds ratio & $2.50 \%$ & $97.50 \%$ \\
\hline \multirow[t]{3}{*}{ Windspeedsqrt } & -0.157 & 0.082 & Air temperature & 1.373 & 1.256 & 1.501 \\
\hline & & & Tmrt & 1.153 & 1.084 & 1.228 \\
\hline & & & Windspeedsqrt & 0.855 & 0.728 & 1.004 \\
\hline
\end{tabular}

b. TSV predicted ordinal thermo-physiological model

\begin{tabular}{|c|c|c|c|c|c|c|}
\hline \\
\hline Slightly cool $=-1$ & 7.739 & 1.000 & Pseudo $R^{2}$ & 0.385 & & \\
\hline Neutral $=0$ & 10.616 & 0.988 & gamma & 0.636 & & \\
\hline Slightly warm = 1 & 12.903 & 1.006 & std. error & 0.024 & & \\
\hline Warm $=2$ & 14.575 & 1.024 & CI & 0.589 & 0.683 & \\
\hline Hot $=3$ & 0.000 & & cor.test & 0.508 & & \\
\hline Air temperature & 0.272 & 0.047 & & Odds ratio & $2.50 \%$ & $97.50 \%$ \\
\hline Tmrt & 0.133 & 0.033 & Air temperature & 1.312 & 1.197 & 1.439 \\
\hline Windspeedsqrt & 0.009 & 0.086 & Tmrt & 1.142 & 1.070 & 1.219 \\
\hline SkW1 = Drops of sweat & 2.308 & 0.317 & Windspeedsqrt & 1.010 & 0.853 & 1.195 \\
\hline SkW2 = Dry & -0.577 & 0.687 & SkW1 = Drops of sweat & 10.054 & 5.400 & 18.730 \\
\hline SkW3 = Just right & -1.522 & 0.130 & SkW2 = Dry & 0.561 & 0.146 & 2.161 \\
\hline SkW4 = Moist & 0.000 & & SkW3 = Just right & 0.218 & 0.168 & 0.282 \\
\hline $\mathrm{E} 1=\mathrm{Yes}$ & 0.001 & 0.125 & $\mathrm{E} 1=\mathrm{Yes}$ & 1.001 & 0.783 & 1.279 \\
\hline \multicolumn{7}{|c|}{ c. TSV predicted ordinal combined parameter model } \\
\hline Slightly cool $=-1$ & 4.158 & 1.086 & Pseudo $R^{2}$ & 0.456 & & \\
\hline Neutral $=0$ & 7.051 & 1.072 & gamma & 0.727 & & \\
\hline Slightly warm = 1 & 9.412 & 1.085 & std. error & 0.021 & & \\
\hline Warm $=2$ & 11.282 & 1.099 & CI & 0.686 & 0.768 & \\
\hline Hot $=3$ & 0.000 & & cor.test & 0.607 & & \\
\hline Air temperature & 0.228 & 0.048 & & & & \\
\hline Tmrt & 0.079 & 0.035 & & Odds ratio & $2.50 \%$ & $97.50 \%$ \\
\hline Windspeedsqrt & -0.200 & 0.089 & Air temperature & 1.256 & 1.147 & 1.384 \\
\hline SkW1 = Drops of sweat & 2.356 & 0.335 & Tmrt & 1.081 & 1.011 & 1.151 \\
\hline SkW2 = Dry & -0.409 & 0.704 & Windspeedsqrt & 0.819 & 0.690 & 0.977 \\
\hline SkW3 = Just right & -1.417 & 0.134 & SkW1 = Drops of sweat & 10.548 & 5.491 & 20.372 \\
\hline SkW4 = Moist & 0.000 & & SkW2 = Dry & 0.664 & 0.166 & 2.617 \\
\hline $\mathrm{E} 1=\mathrm{Yes}$ & -0.028 & 0.129 & SkW3 = Just right & 0.242 & 0.186 & 0.313 \\
\hline SSV1 = Too weak & -0.530 & 0.186 & $\mathrm{E} 1=\mathrm{Yes}$ & 0.972 & 0.755 & 1.251 \\
\hline SSV2 = Little weak & -0.550 & 0.150 & SSV1 = Too weak & 0.588 & 0.407 & 0.838 \\
\hline $\mathrm{SSV} 3=\mathrm{OK}$ & -0.615 & 0.194 & SSV2 = Little weak & 0.577 & 0.430 & 0.778 \\
\hline SSV4 = Little strong & 0.000 & & $\mathrm{SSV} 3=\mathrm{OK}$ & 0.541 & 0.370 & 0.792 \\
\hline SSV5 = Too strong & 1.705 & 0.208 & SSV5 = Too strong & 5.501 & 3.601 & 8.109 \\
\hline
\end{tabular}


Ordinal Regression Model
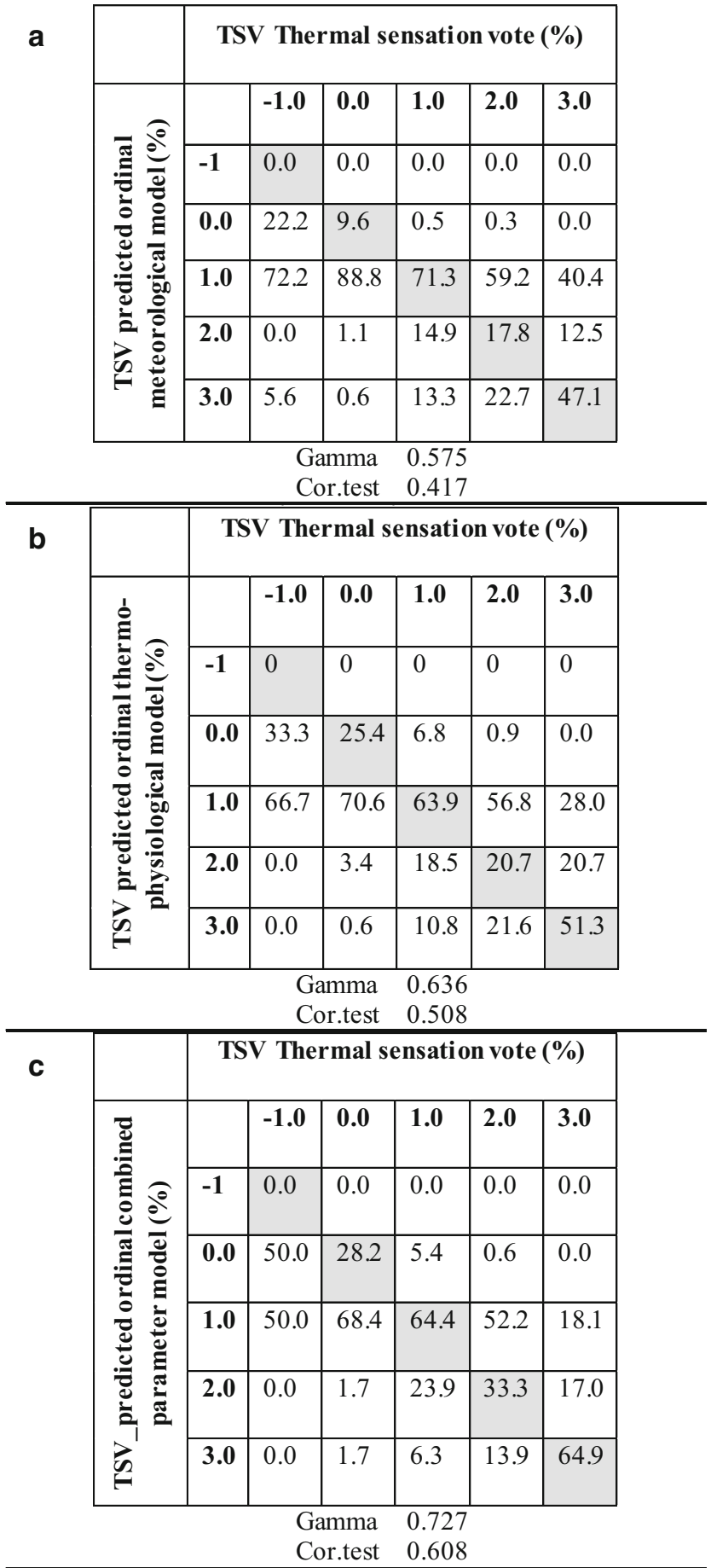

Fig. 4 Cross-tabulation diagram of actual TSV by a ordinal meteorological model, $\mathbf{b}$ ordinal thermo-physiological model and $\mathbf{c}$ ordinal combined parameter model

Consequently, the meteorological model was able to identify the largest group (71.3\%), while not considering the personal or subjective variables. Also, the meteorological model calculated the highest TSV responses in each category $(-1,0,+1$, $+2,+3)$ as the +1 category. In the other two models too, the highest responses in each category were predicted as the +1 category. The predictability of the models in the +1 category reduces when subjective variables are added (in the latter two models) because of improved predictability in the other categories $(0,+2,+3)$.

In a similar study by Lai et al. (2018) in the humid continental climate in Tianjin, China, the $R^{2}$ value of the ordered probability model for predicting TSV was found to be 0.543 . The model was developed using both meteorological and personal parameters. Pantavou \& Lykoudis (2014) have developed an ordinal meteorological model $(\mathrm{Gamma}=0.82)$ and thermo-physiological model $(\mathrm{Gamma}=0.83)$ for predicting TSV for the Mediterranean climate in Athens. The OLR model by Ali and Patnaik (2018) for the tropical city of Bhopal, India, indicates that the predictor explained $33.1 \%$ of the variance $\left(R^{2}=0.331\right)$ of TSV. The model only used meteorological variables.

The $R^{2}$ values in this study, indicates the independent variables can explain about $24.5 \%, 38.5$ and $45.6 \%$ of variation of TSV for the meteorological model, thermo-physiological model and combined parameter model, respectively. A smaller $R^{2}$ does not necessarily imply that estimates of OLR models are biased. However, for meteorological models, it suggests that microclimatic variables alone are not enough to explain human thermal sensation. For the other models, the $R^{2}$ values can differ even among tropical cities due to variation in acclimatisation, behavioural adjustments and psychological adaptation depending on their socio-economic and cultural contexts. These variables are also more difficult to measure.

\section{Conclusion}

Thermal comfort varies depending on the cultural, personal and psychological stimuli alongside the urban microclimate. Therefore, there is a need for new research in this field in different contexts that goes beyond simple physical variables. This study presents an account of outdoor thermal comfort in a high-density tropical context. The focus of the study lies in understanding the link between the subjective thermal sensation and the outdoor thermal environment in the case study context. It combines thermal comfort research with new emerging techniques, such as the application of the ordinal regression method, to understand comfort criteria for the case study context. Comfort surveys were carried out in six different urban areas in summer and autumn seasons. ANOVA analysis showed statistically significant differences between the classes of TSV and all meteorological parameters. People's neutral comfort range is found to be $30.6{ }^{\circ} \mathrm{C} \pm 1.26$. As expected, higher TSV is found to be associated with higher outdoor temperature, globe temperature and mean radiant temperature. Conversely, lower TSV is associated with lower relative humidity and wind speed. 
The research attempted to identify the most important personal parameters responsible for outdoor thermal sensation. Both personal variables (gender, activity, profession-type, exposure to air-conditioned space before survey', 'sweat-levels') and psychological parameters ('reason for visiting the place' and 'next destination air-conditioned') had statistically significant effects on thermal sensation. Other parameters, such as 'age', 'body type', 'body exposure to sun', 'time living in Dhaka', 'travelling in last 30 min', and 'hot food in last 15 min' did not have any significant impact. Weather opinion regarding humidity, wind speed and solar radiation had a significant impact on thermal sensation, although, people's understanding of the humidity situation was slightly confused. Overall, psychological parameters and weather opinions are found to be important factors for understanding human thermal comfort as they construct people's perception which consequently determines their behaviour and activities.

Three models were developed in this study for predicting thermal sensation using the ordinal logistic regression methods. Firstly, models concerning only meteorological parameters were developed. The ordinal meteorological models can explain a $25 \%$ variation in TSV. Subsequently, personal parameters were incorporated to produce a thermophysiological model. Finally, combined parameter models were developed by further incorporating weather opinion factors to the thermo-physiological models. A greater improvement was visible when weather opinions are considered. This is evident from the gamma statistics $0.575,0.636$ and 0.729 for the meteorological, thermo-physiological and combined parameter models, respectively. In each model case, models have shown good predictability, especially in the 'Slightly warm' and 'Hot' categories and lower predictability in the 'Warm' and 'Neutral' categories.

The models show how people's personal backgrounds and subjective responses can affect their thermal sensation levels. The meteorological model is helpful for predicting comfort situations when no personal data or weather opinion is available. The thermo-physiological model could be applied in places with high humidity levels where sweat-levels may vary depending on personal circumstances and thus, have a direct impact on the TSV. Depending on the socio-economic context, other personal variables, such as exposure to air-conditioning, may also be a helpful parameter for understanding the TSV levels. Same is applicable for clothing and gender for places where 'Clo'-value for men is distinctly different from that of women for social reasons. The combined model, on the other hand, could be applicable for medium-rise, medium density, tropical urban areas where pedestrians may be affected by high solar radiation and, therefore, may prefer shaded areas.

The results of this study are helpful in estimating thermal comfort in high-density, tropical contexts, especially in a developing country situation, where the urban microclimate is rapidly deteriorating due to unplanned urban growth. While tourism aspects are not the main concerns for such cities, decent planning of outdoor spaces can have a significant impact on the health and wellbeing of its inhabitants.

Acknowledgements This paper is drawn from research funded by the Schlumberger Foundation at the University of Cambridge, Department of Architecture.

Open Access This article is distributed under the terms of the Creative Commons Attribution 4.0 International License (http:// creativecommons.org/licenses/by/4.0/), which permits unrestricted use, distribution, and reproduction in any medium, provided you give appropriate credit to the original author(s) and the source, provide a link to the Creative Commons license, and indicate if changes were made.

\section{References}

Ahmed KS (2003) Comfort in urban spaces: defining the boundaries of outdoor thermal comfort for the tropical urban environments. Energy and Buildings 35(1):103-110. https://doi.org/10.1016/ S0378-7788(02)00085-3

Ali SB, Patnaik S (2018) Thermal comfort in urban open spaces: objective assessment and subjective perception study in tropical city of Bhopal, India. Urban Climate 24(October 2017):954-967. https:// doi.org/10.1016/j.uclim.2017.11.006

Andrade H, Alcoforado MJ, Oliveira S (2011) Perception of temperature and wind by users of public outdoor spaces: relationships with weather parameters and personal characteristics. Int J Biometeorol 55(5):665-680. https://doi.org/10.1007/s00484-010-0379-0

Azad AK, Kitada T (1998) Characteristics of the air pollution in the city of Dhaka, Bangladesh in winter. Atmos Environ 32(11):1991-2005. https://doi.org/10.1016/S1352-2310(97)00508-6

Begum BA, Biswas SK, Hopke PK (2011) Key issues in controlling air pollutants in Dhaka, Bangladesh. Atmos Environ 45(40):77057713. https://doi.org/10.1016/j.atmosenv.2010.10.022

Brager GS, De Dear RJ (1998) Thermal adaptation in the built environment: a literature review. Energy and Buildings 27:83-96. https:// doi.org/10.1016/S0378-7788(97)00053-4

Carlsen L, Bruggemann R, Kenessov B (2018) Use of partial order in environmental pollution studies demonstrated by urban BTEX air pollution in 20 major cities worldwide. Sci Total Environ 610-611: 234-243. https://doi.org/10.1016/j.scitotenv.2017.08.029

Christensen R (2011) Analysis of ordinal data with cumulative link models - estimation with the ordinal package. R-package version, pp 1-31

Fanger O (1970) Thermal comfort analysis and applications in environmental engineering. McGraw Hill, New York

Ghali K, Ghaddar N, Bizri M (2011) The influence of wind on outdoor thermal comfort in the city of Beirut: a theoretical and field study. HVAC\&R Research 17(March 2015):813-828. https://doi.org/10. 1080/10789669.2011.607746

Givoni B et al 2003 Outdoor comfort research issues. , 35, pp.77-86

da Silveira Hirashima SQ, de Assis ES, Nikolopoulou M (2016) Daytime thermal comfort in urban spaces: a field study in Brazil. Build Environ 107:245-253. https://doi.org/10.1016/j.buildenv.2016.08.006

Ignatius M, Wong NH, Jusuf SK (2015) Urban microclimate analysis with consideration of local ambient temperature, external heat gain, urban ventilation, and outdoor thermal comfort in the tropics. Sustainable Cities and Society 19:121-135. https://doi.org/10. 1016/j.scs.2015.07.016

ISO 7726 1998. Ergonomics of the thermal environment-instruments for measuring physical quantities, Geneva 
Johansson E et al (2018) Outdoor thermal comfort in public space in warm-humid Guayaquil, Ecuador. Int J Biometeorol:1-13. https:// doi.org/10.1007/s00484-017-1329-x

Karjalainen S (2007) Gender differences in thermal comfort and use of thermostats in everyday thermal environments. Build Environ 42(4): 1594-1603. https://doi.org/10.1016/j.buildenv.2006.01.009

Katavoutas G, Theoharatos G, Flocas HA, Asimakopoulos DN (2009) Measuring the effects of heat wave episodes on the human body's thermal balance. Int J Biometeorol 53(2):177-187. https://doi.org/ 10.1007/s00484-008-0202-3

Knez I, Thorsson S, Eliasson I, Lindberg F (2009) Psychological mechanisms in outdoor place and weather assessment: towards a conceptual model. Int J Biometeorol 53(1):101-111. https://doi.org/10. 1007/s00484-008-0194-Z

Kotharkar R, Ramesh A, Bagade A (2018) Urban heat island studies in South Asia: a critical review. Urban Clim. https://doi.org/10.1016/J. UCLIM.2017.12.006

Kruger EL, Drach P (2017) Identifying potential effects from anthropometric variables on outdoor thermal comfort. Build Environ 117: 230-237. https://doi.org/10.1016/j.buildenv.2017.03.020

Krüger EL, Rossi FA (2011) Effect of personal and microclimatic variables on observed thermal sensation from a field study in southern Brazil. Build Environ 46(3):690-697. https://doi.org/10.1016/j. buildenv.2010.09.013

Lai D, Chen C, Liu W, Shi Y, Chen C (2018) An ordered probability model for predicting outdoor thermal comfort. Energ Buildings 168: 261-271. https://doi.org/10.1016/j.enbuild.2018.03.043

Lin TP (2009) Thermal perception, adaptation and attendance in a public square in hot and humid regions. Build Environ 44(10):2017-2026. https://doi.org/10.1016/j.buildenv.2009.02.004

McIntyre DA (1980) Indoor climate. Applied Science Publishers, London

Metje N, Sterling M, Baker CJ (2008) Pedestrian comfort using clothing values and body temperatures. J Wind Eng Ind Aerodyn 96(4):412435. https://doi.org/10.1016/j.jweia.2008.01.003

$\mathrm{Ng}$ E, Cheng V (2012) Urban human thermal comfort in hot and humid Hong Kong. Energ Buildings 55:51-65. https://doi.org/ 10.1016/j.enbuild.2011.09.025

Nikolopoulou M, Baker N, Steemers K (2001) Thermal comfort in outdoor urban spaces: understanding the human parameter. Sol Energy 70(3):227-235. https://doi.org/10.1016/S0038-092X(00) 00093-1
Nikolopoulou M, Lykoudis S (2006) Thermal comfort in outdoor urban spaces: analysis across different European countries. Build Environ 41(11):1455-1470. https://doi.org/10.1016/j.buildenv.2005.05.031

Nikolopoulou M, Lykoudis S, Kikira M (2003) Thermal comfort in outdoor spaces: field studies in Greece. Proceedings of the fifth international conference on urban climate, Lodz, pp. 1-5

Nikolopoulou M, Steemers K (2003) Thermal comfort and psychological adaptation as a guide for designing urban spaces. Energ Buildings 35(1):95-101. https://doi.org/10.1016/S0378-7788(02)00084-1

Pantavou K, Theoharatos G, Santamouris M, Asimakopoulos D (2013) Outdoor thermal sensation of pedestrians in a Mediterranean climate and a comparison with UTCI. Build Environ 66:82-95. https://doi. org/10.1016/j.buildenv.2013.02.014

Pantavou K, Lykoudis S (2014) Modeling thermal sensation in a Mediterranean climate-a comparison of linear and ordinal models. Int J Biometeorol 58(6):1355-1368. https://doi.org/10.1007/ s00484-013-0737-9

Santamouris M, Asimakopoulos DN (2001) Energy and climate in the urban built environment. James and James Science Publishers, London

Schellen L, Loomans MGLC, de Wit MH, Olesen BW, Lichtenbelt WDM (2012) The influence of local effects on thermal sensation under non-uniform environmental conditions-gender differences in thermophysiology, thermal comfort and productivity during convective and radiant cooling. Physiol Behav 107(2):252-261. https:// doi.org/10.1016/j.physbeh.2012.07.008

Thorsson S et al (2007) Different methods for estimating the mean radiant temperature in an outdoor urban setting. Int J Climatol 1993(October):1983-1993. https://doi.org/10.1002/joc

Thorsson S, Lindqvist M, Lindqvist S (2004) Thermal bioclimatic conditions and patterns of behaviour in an urban park in Goteborg, Sweden. Int J Biometeorol 48(3):149-156. https://doi.org/10.1007/ s00484-003-0189-8

Turok I, McGranahan G (2013) Urbanization and economic growth: the arguments and evidence for Africa and Asia. Environ Urban 25(2): 465-482. https://doi.org/10.1177/0956247813490908

Villadiego K, Velay-Dabat MA (2014) Outdoor thermal comfort in a hot and humid climate of Colombia: a field study in Barranquilla. Build Environ 75:142-152. https://doi.org/10. 1016/j.buildenv.2014.01.017

Yang W, Wong NH, Jusuf SK (2013) Thermal comfort in outdoor urban spaces in Singapore. Build Environ 59:426-435. https://doi.org/10. 1016/j.buildenv.2012.09.008 